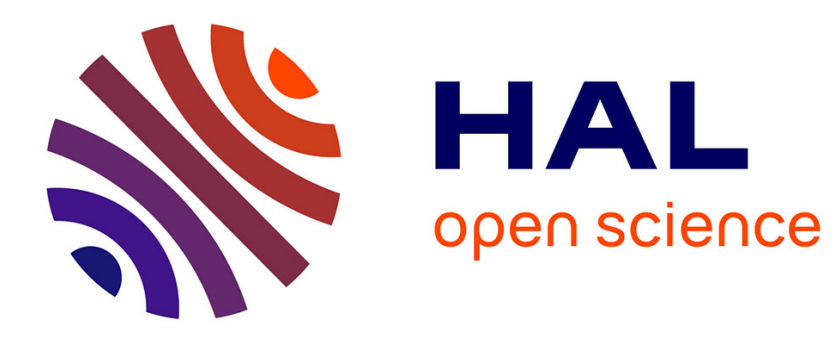

\title{
17. Température critique de films supraconducteurs désordonnés de plomb et d'étain
}

\author{
N. Barth, K. Knorr
}

\section{To cite this version:}

N. Barth, K. Knorr. 17. Température critique de films supraconducteurs désordonnés de plomb et d'étain. Revue de Physique Appliquée, 1970, 5 (6), pp.905-905. 10.1051/rphysap:0197000506090502 . jpa-00243487

\section{HAL Id: jpa-00243487 https://hal.science/jpa-00243487}

Submitted on 1 Jan 1970

HAL is a multi-disciplinary open access archive for the deposit and dissemination of scientific research documents, whether they are published or not. The documents may come from teaching and research institutions in France or abroad, or from public or private research centers.
L'archive ouverte pluridisciplinaire HAL, est destinée au dépôt et à la diffusion de documents scientifiques de niveau recherche, publiés ou non, émanant des établissements d'enseignement et de recherche français ou étrangers, des laboratoires publics ou privés. 


\section{TEMPÉRATURE CRITIQUE DE FILMS SUPRACONDUCTEURS DÉSORDONNÉS DE PLOMB ET D'ÉTAIN}

\section{N. BARTH et K. KNORR}

Les films de plomb et d'étain, évaporés sur un substrat refroidi, présentent un haut degré de désordre cristallin, qui peut de plus être augmenté par l'addition d'impuretés.

Alors que la température critique de l'étain désordonné augmente de $3,6{ }^{\circ} \mathrm{K}$ à $6,8^{\circ} \mathrm{K}$, celle du plomb est réduite de $7,2 \mathrm{o}$ à $6,5 \mathrm{o}$.
Ces comportements opposés peuvent être interprétés de façon satisfaisante par la modification des paramètres $\lambda,\langle\omega\rangle,\left\langle\omega^{2}\right\rangle \mu^{*}[1]$ que les mesures d'effet tunnel permettent de mesurer.

[1] Mc Millan (W. L.), Phys. Rev., 1968, 167/331.

\begin{tabular}{|c|c|c|c|c|c|c|}
\hline & $\begin{array}{l}T_{\mathrm{e}} \\
{ }_{\mathrm{o}} \mathrm{K}\end{array}$ & $\lambda$ & $\begin{array}{l}<\omega> \\
(\mathrm{meV})\end{array}$ & $\begin{array}{l}\left\langle\omega^{2}>\right. \\
(\mathrm{meV})^{2}\end{array}$ & $\mu^{*}$ & $\begin{array}{l}T_{\mathrm{c}} \text { (théor.) } \\
\left({ }^{\circ} \mathrm{K}\right)\end{array}$ \\
\hline $\begin{array}{r}\mathrm{Pb} \text { Condensé à } 2{ }^{\circ} \mathrm{K} \\
\text { recuit à } 300^{\circ} \mathrm{K}\end{array}$ & 7,2 & 1,66 & 4,50 & 25,8 & 0,12 & 5,8 \\
\hline $\mathrm{Pb}$ Condensé à $2{ }^{\circ} \mathrm{K}$ & 7,2 & 1,91 & 3,74 & 21,0 & 0,08 & 5,7 \\
\hline $\begin{array}{l}\mathrm{Pb}+10 \% \mathrm{Cu} \\
\text { Condensé à } 2 \% \mathrm{~K}\end{array}$ & 6,5 & 2,01 & 3,03 & 16,3 & 0,04 & 5,2 \\
\hline $\begin{array}{r}\text { Sn Condensé à } 2{ }^{\circ} \mathrm{K} \\
\text { Recuit à } 300^{\circ} \mathrm{K}\end{array}$ & 3,6 & 0,70 & 9,4 & 108 & 0,116 & 2,3 \\
\hline Sn Condensé à $2{ }^{\circ} \mathrm{K}$ & 4,5 & 0,84 & 7,9 & 86,5 & 0,07 & 4,2 \\
\hline $\begin{array}{l}\mathrm{Sn}+10 \% \mathrm{Cu} \\
\text { Condensé à } 2 \% \mathrm{~K}\end{array}$ & 6,8 & 1,82 & 3,92 & 31,7 & 0,04 & 6,2 \\
\hline
\end{tabular}

